\title{
Development of an Artificial Placenta: Endocrine Responses of Goat Fetuses during Long-Term Extrauterine Incubation with Umbilical Arteriovenous Extracorporeal Membrane Oxygenation
}

\author{
NobuYa UNNO, Yoshinori KUWABARA*, YUmiko NARUMIYA-TAKIKAWA, \\ Kiminiro TAKECHI, Haruo MASUDA, Yoshiko OGAMI, Ruriko TSUSHIMA, \\ Masato SAKAI, Takashi OKAI, Shiro KOZUMA, KazUnori BABA**, \\ AND YUJI TAKETANI \\ Laboratory of Perinatal Medicine, Department of Obstetrics and Gynecology, \\ Faculty of Medicine, The University of Tokyo, Tokyo 113, \\ *Department of Obstetrics and Gynecology, Faculty of Medicine, Juntendo University, Tokyo 113, and \\ **Institute of Medical Electronics, Faculty of Medicine, The University of Tokyo, Tokyo 113, Japan
}

\begin{abstract}
To investigate endocrine responses of isolated premature goat fetuses during long-term extrauterine incubation with umbilical arteriovenous extracorporeal membrane oxygenation (A-V ECMO), we conducted experiments in seven goat fetuses (95-134 days gestation). The fetuses were cannulated from the umbilical vessels, and their blood-gas exchange was totally supported by A-V ECMO, while they were maintained in an isothermal incubator containing artificial amniotic fluid. The survival period was between 84 and $190 \mathrm{~h}$. At 24-h intervals, fetal blood samples were collected, and plasma concentrations of catecholamines, ACTH, and cortisol were determined. After $24 \mathrm{~h}$ of incubation, fetal circulatory and respiratory variables remained stable, until evident circulatory failure occurred before their deaths. A similar pattern was observed in temporal changes in plasma concentrations of catecholamines, ACTH, and cortisol. Plasma levels were high during the initial $24 \mathrm{~h}$ of incubation, subsequently decreased, and then increased before death. Hormone levels during stable periods were equivalent to or slightly higher than values for fetuses in utero. These results suggest that conditions during the stable period of long-term extracorporeal fetal incubation are not highly stressful for the isolated fetuses.
\end{abstract}

Key words: Catecholamines, Adrenocorticotropic hormone, Cortisol, Renal dysfunction, Extrauterine fetal incubation

(Endocrine Journal 41(Suppl): S69-S76, 1994)

IN PREVIOUS reports, we described the development of an extrauterine fetal incubation (EUFI) system using arteriovenous extracorporeal membrane oxygenation (A-V ECMO) via umbilical vessels $[1,2]$. We conducted experiments on longterm incubation of isolated premature goat fetuses in this system. We maintained previable goat fe-

Correspondence to: Dr. Nobuya UNNO, Department of Obstetrics and Gynecology, International Medical Center of Japan, 1-21-1 Toyama, Shinjuku-ku, Tokyo 162, Japan tuses for more than a week and clarified that oxygen consumption of a fetus in EUFI was almost equal to that of a fetus in utero [3, 4]. However, many problems still remained. All of the EUFI experiments were terminated with fetal deaths. The causes of death included catheter malfunction, ventricular tachycardia, intraperitoneal bleeding, and circulatory insufficiency. Even in cases without accidents, marked water retention and circulatory failure occurred in a few days, although the circulatory and respiratory conditions 
of the fetuses during the incubation seemed stable. Therefore, we planned a new series of the longterm EUFI experiments to determine endocrine response and renal function of the fetus. The objective of this study was to evaluate conditions of the exteriorized fetuses by measuring temporal profiles of stress-reactive hormones and to determine the possible causes of water retention and circulatory deterioration.

\section{Materials and Methods}

\section{Animal preparations}

We performed cesarean sections on seven pregnant goats and connected their fetuses (weight 0.5 to $2.5 \mathrm{~kg}$; 95 days to 134 days; term 148 days) to an ECMO circuit. The details of surgical procedure have been described elsewhere [2,3]. Briefly, hysterotomy was performed under general anesthesia. The hind legs and lower half of the trunk of the fetus were extracted, and the umbilicus was fully exposed. An umbilical artery and vein were isolated. A polyvinyl catheter was inserted through an arteriotomy and advanced beyond the bifurcation of the abdominal aorta. A similar technique was performed on the umbilical vein, and the catheter was positioned $2 \mathrm{~cm}$ beyond the umbilicus. As soon as the catheters were connected to the extracorporeal circuit, the A-V ECMO was started. During this procedure, partial placental circulation maintained the change of fetal blood gases via the remaining umbilical artery and vein because the goat has 2 arteries and 2 veins in its umbilicus. The remaining pair of umbilical vessels were cannulated and connected to the circuit. After the catheterization was completed, the fetus was transferred into an incubator containing artificial amniotic fluid warmed to $39.5^{\circ} \mathrm{C}$.

\section{The incubation system}

The extracorporeal circuit consisted of an arterial open-top reservoir, a roller pump, a nonmicroporous membrane oxygenator made of silicone hollow fibers, a closed reservoir, and a heat exchanger (Fig. 1). The oxygenator had a functional surface area for gas exchange of $0.5 \mathrm{~m}^{2}$ (Senko Medical Instrument Manufacturing Co., Ltd., Tokyo, Japan). The priming volume of the circuit was approximately $230 \mathrm{ml}$. The priming solution consisted of whole blood that was anticoagulated with heparin and balanced appropriately for $\mathrm{pH}, \mathrm{Na}, \mathrm{K}$, and $\mathrm{Ca}$. Fetal blood from the umbilical arteries drained into the arterial reservoir. The blood flow of the circuit was regulated by a flow-control system to maintain a constant blood volume in the arterial reservoir. The blood was completely oxygenated and returned to the umbilical veins via the closed reservoir and heat exchanger.

\section{Fetal monitoring}

A catheter was inserted into an internal carotid artery, and the arterial blood pressure (aBP) waveform was monitored continuously. A polygraph (No. 362, Nihondenki-Sanei Co., Ltd., Tokyo, Japan) continuously recorded the $\mathrm{aBP}$ and heart rate (HR), extracorporeal circulatory blood flow (ECC), and oxygen saturation of arterial blood $\left(\mathrm{SaO}_{2}\right)$ that were determined by the arterial catheter waveform, electromagnetic flowmeter, and in-line saturation probe, respectively. Blood gas tensions and $\mathrm{pH}$ were measured with a $170 \mathrm{pH} /$ Blood Gas Analyzer (Ciba Corning Diagnostics Corp., Medfield, MA, USA). Pre- and post-oxygenated blood samples were obtained at 3 to 6-h intervals, and $\mathrm{pH}, \mathrm{pCO}_{2}$, $\mathrm{pO}_{2}, \mathrm{SaO}_{2}$, and hemoglobin were measured. Preoxygenated and post-oxygenated blood oxygen content $\left(\mathrm{C}-\mathrm{O}_{2}\right)$, oxygen delivery (OD) and fetal whole body oxygen consumption (OC) were calculated according to the following formulas:

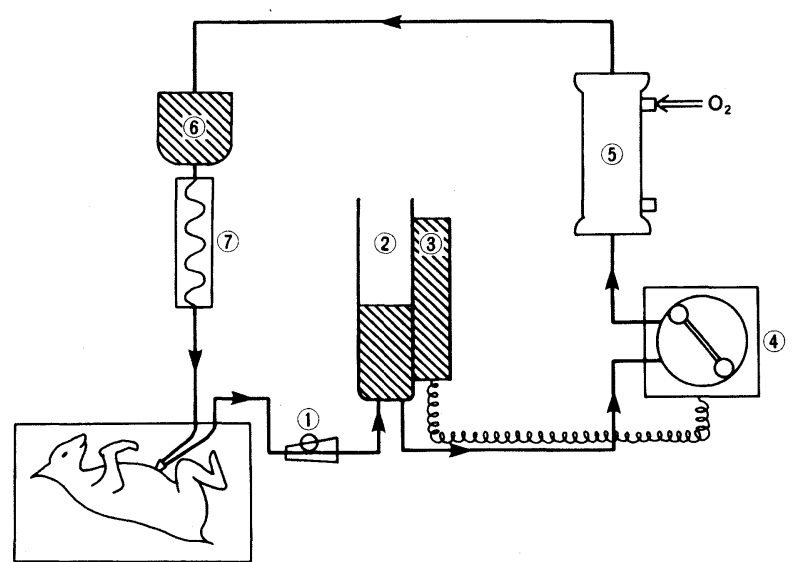

Fig. 1. Extracorporeal blood circuit of the extrauterine fetal incubation system. (1)Tube occluder, (2)arterial opentop reservoir, (3) flow detector-controller, (4) blood pump,(5)silicone hollow-fiber membrane oxygenator, (6) closed reservoir, (7) heat exchanger. 
$\mathrm{C}-\mathrm{O}_{2}=1.34 \times \mathrm{Hb} \times \mathrm{SaO}_{2} / 100+0.003 \times \mathrm{PO}_{2}$

$\mathrm{OD}=$ post $-\mathrm{C}-\mathrm{O}_{2} \times \mathrm{ECC} / 100 / \mathrm{BW}$

$\mathrm{C}=\left(\right.$ post $-\mathrm{C}-\mathrm{O}_{2}-$ pre $\left.-\mathrm{C}-\mathrm{O}_{2}\right) \times \mathrm{ECC} / 100 / \mathrm{BW}$

At 24-h intervals, $8 \mathrm{ml}$ of fetal blood was collected from the umbilical artery. The same amount of donor blood was infused simultaneously into the arterial reservoir. The blood was immediately transferred to an iced tube containing EDTA-2Na and centrifuged at $3000 \mathrm{rpm}$ for $20 \mathrm{~min}$ at $4^{\circ} \mathrm{C}$. The plasma was stored at $-80^{\circ} \mathrm{C}$ until assayed. Plasma concentrations of norepinephrine, epinephrine, ACTH, and cortisol were determined. From the temporal profile of each hormone, we assessed fetal responses to the extrauterine environment. We also determined plasma concentrations of urea nitrogen (BUN) and creatinine (CRE) to evaluate fetal renal function during EUFI.

Maternal blood was obtained during hysterotomy, and the plasma was stored for later determination of catecholamines, ACTH, cortisol, BUN, and CRE. When the goat had twins, cord blood of the sibling was also obtained and processed.

\section{Fetal conditions during incubation}

In the initial $24 \mathrm{~h}$ of incubation, the ECC was controlled by changing the resistance and impedance of the arterial portion of the circuit through adjustments in the height of the arterial reservoir or the compliance of the circuit with a tube occluder (Fig. 1). The ECC was set within the range of 60 to $130 \mathrm{ml} / \mathrm{min} / \mathrm{kg}$ estimated body weight (BW) that was estimated as the optimal ECC for this system in our previous study [4].

Heparin solution ( 400 units $/ \mathrm{ml}$ ) was continuously infused into the circuit to keep the activated coagulation time between 180 and $250 \mathrm{sec}$. The amount of heparin needed was 40 to 60 units $/ \mathrm{kg} /$ h.

The incubator containing artificial amniotic fluid was heated to maintain fetal body temperature around $39.5^{\circ} \mathrm{C}$. A solution containing $30 \%$ glucose, $3 \%$ amino acids and $1.5 \%$ soy bean oil was administered at a rate of $2 \mathrm{ml} / \mathrm{h} / \mathrm{kg}$; this amounted to $70 \mathrm{kcal} / \mathrm{kg} /$ day.

The fetus was maintained without anesthesia. The catheter between the fetus and the blood circuit was long enough for unrestrained movement.

\section{Assay methods}

Plasma catecholamine concentrations were measured with a fully automated HPLC-fluorometric system (Model HLC-8030 Catecholamine Analyzer, Tosoh, Tokyo, Japan) by the diphenylethylenediamine condensation method [5]. The plasma ACTH level was measured by immunoradiometric assay using ACTH-II IRMA kit (MitsubishiYuka Co. Ltd. Tokyo, Japan)[6]. Plasma cortisol concentrations were determined with the SPAC-S Cortisol kit (Daiichi Radioisotope Labs.,Ltd., Tokyo, Japan), which is a reagent set for the solidphase competitive radioimmunoassay of cortisol that contains tubes coated with cortisol monoclonal antibody. BUN was determined by the diacetyl monooxim method using Fearon reaction. CRE was assayed by a modified Folin-Wu method with Jaffe reaction.

We calculated the mean values of ECC, $\mathrm{HR}, \mathrm{aBP}$, hemoglobin, $\mathrm{SaO}_{2}, \mathrm{PaO}_{2}, \mathrm{PaCO}_{2}, \mathrm{OD}$ and $\mathrm{OC}$ in each fetus during the mid-period (the incubation period excluding the initial and the last $24 \mathrm{~h}$ ). The experiment were continued until fetal death. After death, we determined the dry body weight. At autopsy, lack of lung aeration and patency of ductus arteriosus were confirmed. The most probable cause of death was estimated from the findings during the incubation and at autopsy.

Data were expressed as the mean \pm standard deviation (SD). For statistical analysis of BUN and $C R E$, the unpaired Student- $t$ test was applied. $P<0.05$ was regarded as significant.

\section{Results}

\section{Profile of long-term EUFI of isolated goat fetuses}

Data for the seven goat fetuses that underwent long-term EUFI are summarized in Table 1 . The incubation period ranged from 84 to $190 \mathrm{~h} \mathrm{(140 \pm}$ $42 \mathrm{~h}$ ). Many factors were related to death; they could be summarized as problems related to extracorporeal circulation, including catheter malfunction, liver injury from the venous catheter tip, and circulatory failure that occurred after 3 to 7 days of extrauterine incubation. Marked water retention, including pleural effusions, ascites and subcutaneous edema, developed after 3 to 5 days of incubation in all the experiments. 
Mean ECC, HR, and aBP of the individual fetuses are shown in Table 2. Mean ECC ranged from 64 to $155 \mathrm{ml} / \mathrm{min} / \mathrm{kg}$. In experiment 7 , the mean ECC exceeded the maximum optimal level of 130 $\mathrm{ml} / \mathrm{min} / \mathrm{kg}$. The mean HR ranged from 176 to $204 \mathrm{bpm}$. The HRs of the isolated goat fetuses in this series of EUFI tests were greater than those reported in studies using in-utero fetuses [7-10]. The mean aBPs were between 43.8 and $50.0 \mathrm{mmHg}$, values compatible with those seen in in-utero fetuses.

Mean values for hemoglobin, $\mathrm{SaO}_{2}, \mathrm{PaO}_{2}, \mathrm{PaCO}_{2}$ and $\mathrm{pH}$ are also listed in Table 2. The mean hemoglobin and $\mathrm{PaCO}_{2}$ were lower than values reported in-utero. The mean values of $\mathrm{SaO}_{2}$ and $\mathrm{PaO}_{2}$ were slightly higher than for fetuses in-utero. The $\mathrm{pH}$ values were within the normal range. Metabolic acidosis was not observed in any experiment during the mid-period of EUFI. Table 2 shows mean values of $O D$ and $O C$ during the midperiod of EUFI in each of the seven fetuses. The OD was more than $10 \mathrm{ml} / \mathrm{min} / \mathrm{kg}$ in all experiments. The OC ranged from 5.5 to $7.8 \mathrm{ml} / \mathrm{min} /$ $\mathrm{kg}$. These values were at the same level that we previously reported [3] and slightly lower than the values of the fetuses in-utero.

\section{Endocrine changes during long-term EUFI}

In Figs. 2-7, the broken lines represent data obtained from fetuses of 122 days' gestation or less (Group I), and solid lines are for fetuses of 128 days' gestation or more (Group II). Plasma concentration of norepinephrine fluctuated, and it was higher than values reported in chronically instrumented lamb fetuses (Fig. 2)[11-13]. An initial elevation and subsequent decrease was observed in epinephrine levels (Fig. 3), and values during the mid-period were equivalent to those reported before [11-13]. An initial rise and subsequent decline in plasma ACTH were clearly observed in all fetuses. A moderate ACTH increase before fetal death was also observed in some cases (Fig. 4). Basal levels observed in the mid-period were equal to values reported in lamb fetuses [14-16]. Cortisol concentration was not so simple. A mild elevation of basal levels in the mid-period was suspected; however, the temporal profile was similar

Table 1. Animal profiles

\begin{tabular}{rrrrrr}
\hline $\begin{array}{c}\text { Age } \\
\text { (days) }\end{array}$ & $\begin{array}{c}\text { Body Weight } \\
\text { (kg) }\end{array}$ & \multicolumn{2}{c}{$\begin{array}{c}\text { Incubation Period } \\
\text { (h }\end{array}$ min) } & Cause of Death \\
\hline 1 & 134 & 2.5 & 159 & 7 & Catheter malfunction \\
2 & 110 & 1.2 & 107 & 52 & Catheter malfunction \\
3 & 95 & 0.5 & 188 & 8 & Circulatory failure \\
4 & 128 & 2.5 & 190 & 32 & Circulatory failure \\
5 & 122 & 2.3 & 158 & 0 & Circulatory failure \\
6 & 128 & 1.7 & 84 & 4 & Liver injury \\
7 & 116 & 1.3 & 91 & 0 & Circulatory failure \\
\hline
\end{tabular}

Table 2. Conditions of fetuses during the mid-period of EUFI

\begin{tabular}{|c|c|c|c|c|c|c|c|c|c|c|c|c|}
\hline & $\begin{array}{c}\text { ECC } \\
(\mathrm{ml} / \mathrm{min} / \mathrm{kg})\end{array}$ & $\begin{array}{l}\text { Heart Rate } \\
\quad \text { (bpm) }\end{array}$ & $\begin{array}{c}\mathrm{aBP} \\
(\mathrm{mmHg})\end{array}$ & $\mathrm{n}$ & $\begin{array}{l}\mathrm{HB} \\
(\mathrm{g} / \mathrm{d} l)\end{array}$ & $\begin{array}{c}\mathrm{SaO}_{2} \\
(\%)\end{array}$ & $\begin{array}{c}\mathrm{PaO}_{2} \\
\text { (mmHg) }\end{array}$ & $\begin{array}{c}\mathrm{PaCO}_{2} \\
(\mathrm{mmHg})\end{array}$ & $\mathrm{pH}$ & $\begin{array}{c}\text { OD } \\
(\mathrm{ml} / \mathrm{min} / \mathrm{kg})\end{array}$ & $O C$ & $\mathrm{n}$ \\
\hline & $63.6 \pm 14.3$ & $176 \pm 16$ & $50.0 \pm 5.0$ & 43 & $12.9 \pm 0.6$ & $47.1 \pm 11.9$ & $23.8 \pm$ & $5.3 \pm 8.7$ & $7.326 \pm 0.064$ & & & \\
\hline & $91.8 \pm 7.2$ & $195 \pm 9$ & $43.8 \pm 8.6$ & 40 & $12.1 \pm 0.4$ & $51.4 \pm 8.7$ & $27.8 \pm$ & $40.3 \pm$ & $7.340 \pm 0.030$ & & $7.3 \pm 0.7$ & \\
\hline & & & not measured & 27 & $12.3 \pm 0.4$ & $66.1 \pm 10.1$ & & $386+$ & $7.367 \pm 0.032$ & & \pm 1.0 & \\
\hline & $115.2 \pm 13.8$ & & & 21 & & $4 \pm 9.7$ & & & $449 \pm 0.043$ & & $5.7 \pm 1.5$ & \\
\hline & $95.4 \pm 15.7$ & $192 \pm 11$ & $45.3 \pm 5.4$ & 27 & $9.0 \pm 0.6$ & $56.1 \pm 8.5$ & $30.4 \pm$ & & $305 \pm 0.072$ & & & \\
\hline & $119.8 \pm 8.9$ & $204 \pm 7$ & $48.0 \pm 2.9$ & 8 & $9.9 \pm 0.3$ & $62.1 \pm 5.9$ & $31.2 \pm 2.5$ & $42.4 \pm 4.6$ & $7.351 \pm 0.043$ & $17.0 \pm 1.8$ & $7.1 \pm 0.4$ & \\
\hline & $155.0 \pm 6.7$ & $183 \pm 14$ & not measured & 9 & $10.9 \pm 2.3$ & $71.7 \pm 3.2$ & $36.8 \pm 2.0$ & $43.3 \pm 3.0$ & $7.381 \pm 0.031$ & $24.2 \pm 1.3$ & $7.8 \pm 0.3$ & \\
\hline
\end{tabular}

ECC, extracorporeal circulatory blood flow; $\mathrm{aBP}$, arterial blood pressure; $\mathrm{Hb}$, hemoglobin concentration; $\mathrm{SaO}_{2}$, arterial oxygen saturation; $\mathrm{OD}$, oxygen delivery; $\mathrm{OC}$, oxygen consumption; $n$, number of the samples; Data are expressed as mean $\pm \mathrm{SD}$. 
to that of ACTH (Fig. 5). In norepinephrine and cortisol, plasma concentration was higher, and its temporal changes were more evident in the fetuses of Group II than those of the fetuses of Group

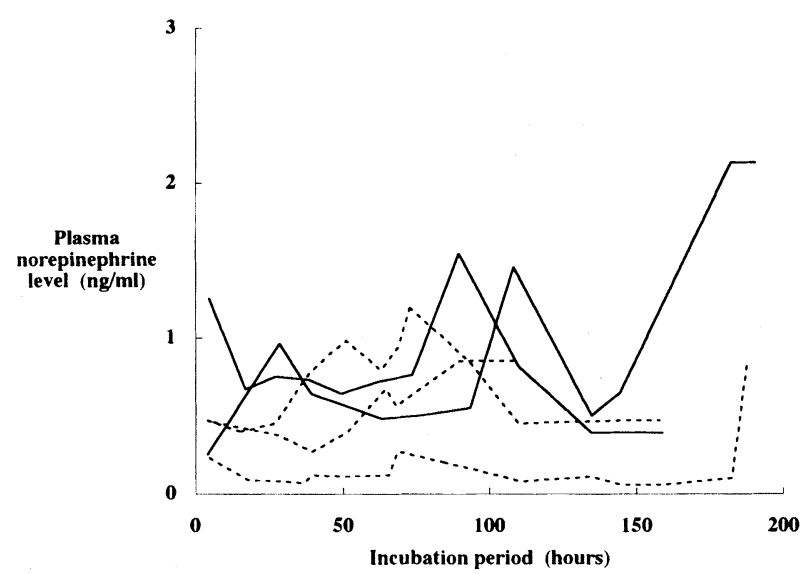

Fig. 2. Plasma norepinephrine levels of goat fetuses during long-term extrauterine incubation experiments. Levels were slightly higher than the values reported for fetuses in-utero. Broken and solid lines represent data obtained from fetuses of less than 122 days' gestation and more than 128 days' gestation, respectively.

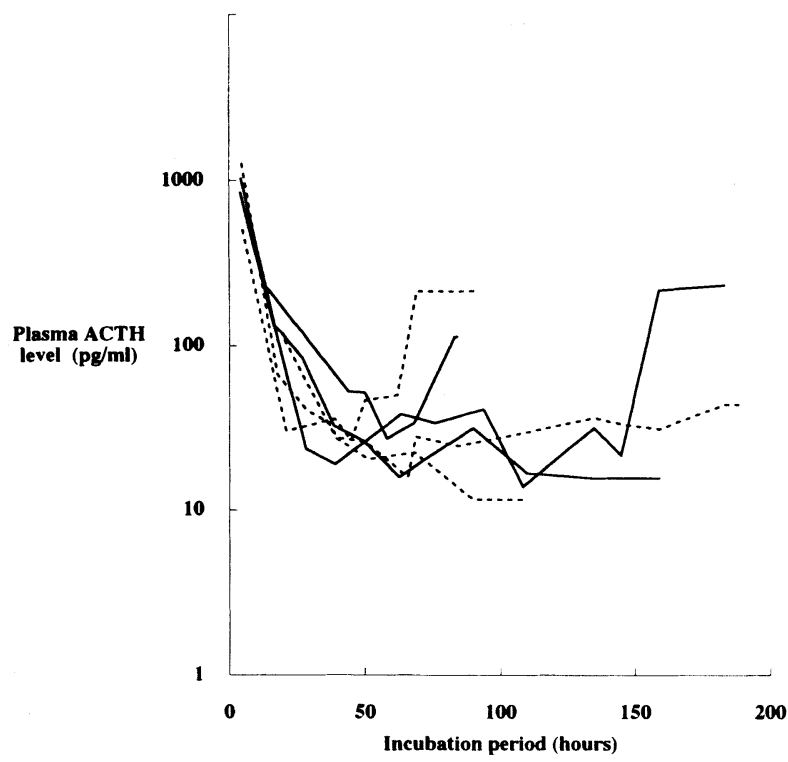

Fig. 4. Plasma ACTH levels of goat fetuses during longterm extrauterine incubation experiments. Basal levels during the mid-period were equivalent to those reported for fetuses in-utero. The initial high levels were observed in all cases.
I. However, in epinephrine and $\mathrm{ACTH}$, we could not find any difference by age in their profiles.

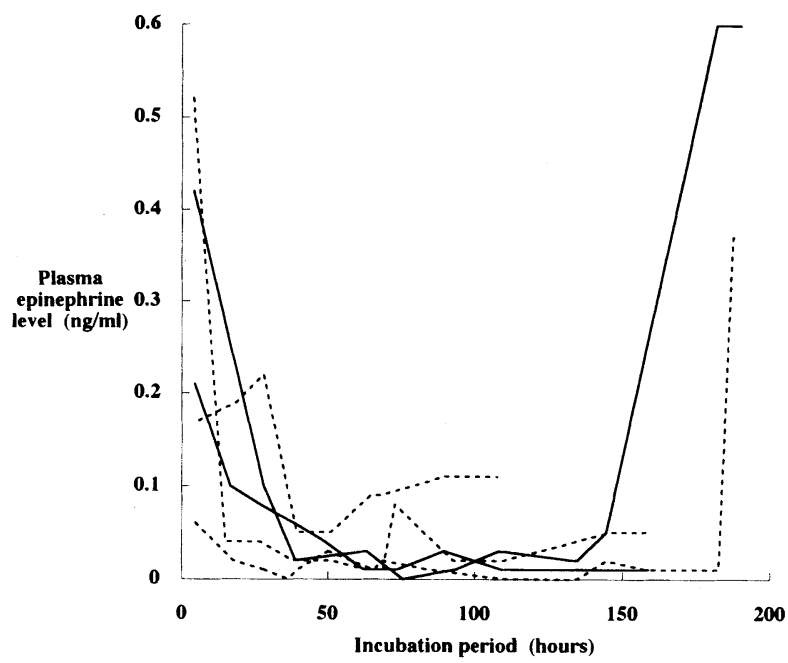

Fig. 3. Plasma epinephrine levels of goat fetuses during long-term extrauterine incubation experiments. Levels of epinephrine during the mid-period were equivalent to those reported for fetuses in-utero. The initial high levels indicate the stimuli due to introduction of the extra-corporeal circulation.

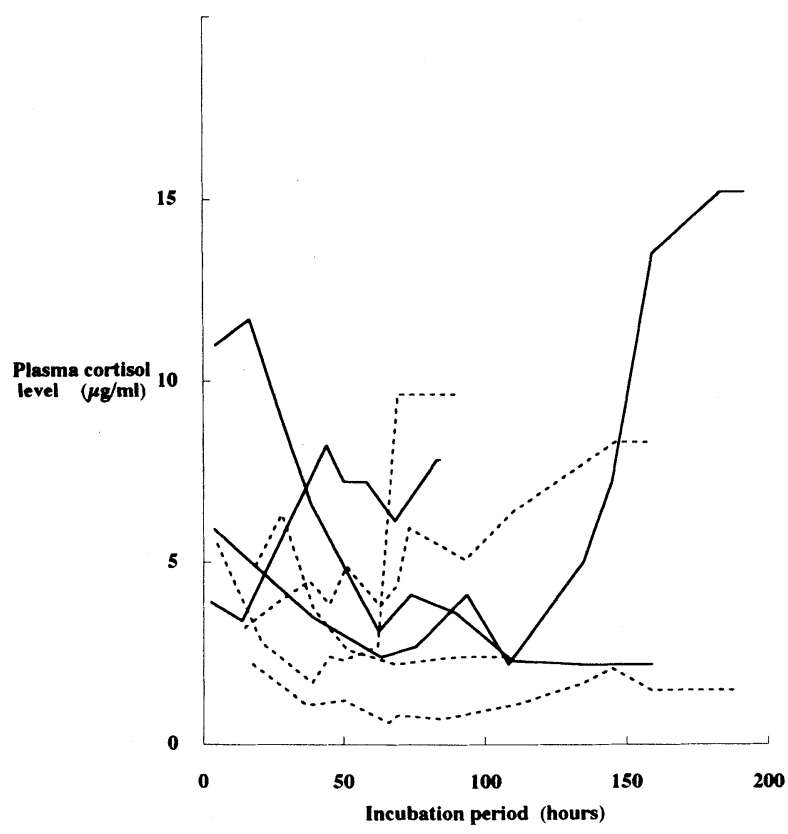

Fig. 5. Plasma cortisol levels of goat fetuses during longterm extrauterine incubation experiments. 


\section{Renal function during long-term EUFI}

Eleven maternal plasma samples and 6 sibling samples were collected at mean gestation ages of $117.7 \pm 11.5$ and $122.3 \pm 11.4$ days, respectively. Maternal values of BUN were $23.7 \pm 5.8 \mathrm{mg} / \mathrm{d} l$, while CRE was $0.72 \pm 0.22 \mathrm{mg} / \mathrm{d} l$. Sibling values of BUN and CRE were $25.5 \pm 4.3$ and $1.13 \pm 0.39$ $\mathrm{mg} / \mathrm{d} l$, respectively. Maternal and sibling BUN levels were not statistically different, but CRE was significantly higher in sibling samples than maternal samples. Figures 6 and 7 illustrate the temporal profiles of BUN and CRE during long-term EUFI. In 4 fetuses (experiment 1, 2, 3, 5), BUN and CRE increased during the initial $40 \mathrm{~h}$ of incubation then subsequently decreased, and in 3 fetuses (experiment $4,6,7)$; they steadily decreased from the start of incubation. Initial levels of BUN and CRE were slightly higher or equal to those in sibling samples. After $60 \mathrm{~h}$ of incubation, BUN and CRE elevated in some cases.

\section{Discussion}

Exteriorized premature fetuses experienced drastic environmental changes during the transition period. However, after 24 to $36 \mathrm{~h}$ of incubation, circulatory variables of the animals became stable. Values of OD exceeded $10 \mathrm{ml} / \mathrm{min} / \mathrm{kg}$, the critical oxygen delivery level to maintain basal metabolism of exteriorized goat fetuses with A-V ECMO

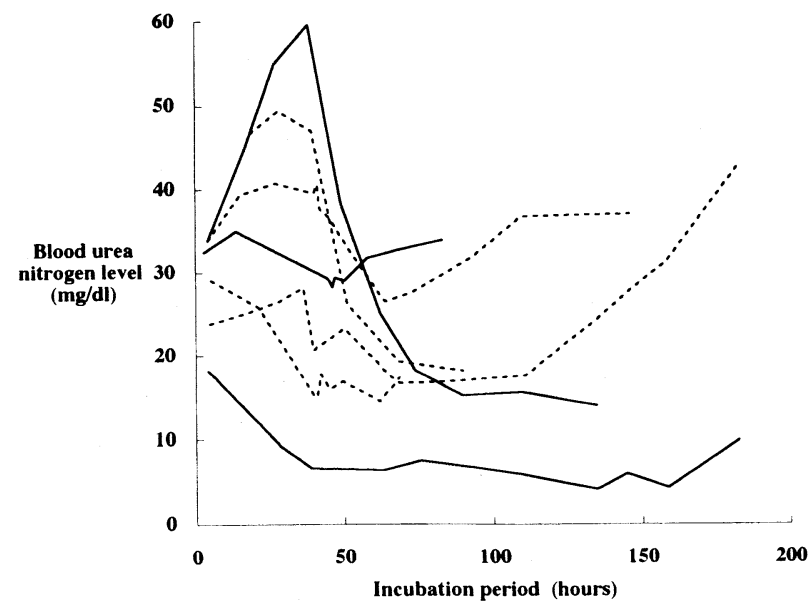

Fig. 6. Blood urea nitrogen concentration of goat fetuses during long-term extrauterine incubation experiments.
[3]. Most physiological variables listed in Table 2 were comparable with fetuses in utero. A tendency for tachycardia was observed; however, $\mathrm{aBP}$, $\mathrm{PaCO}_{2}$ and $\mathrm{pH}$ were at normal levels for fetuses. Neither metabolic acidosis nor reduced OC were observed during the mid-period of incubation; therefore, the circulatory system, including peripheral circulation, was maintained well. It was reported that the responsiveness of norepinephrine to external stimuli matures earlier than that of epinephrine [11] and that adrenocortical responsiveness is at low level during the prenatal period $[17,18]$. We found high levels and transient elevations in plasma norepinephrine during EUFI, while epinephrine, ACTH, and cortisol had similar temporal profiles. Mild activation of norepinephrine indicates that the condition of the animals was not completely stable during EUFI. However, the patterns of epinephrine, ACTH, and cortisol suggest that the environment during the mid-period was tolerable for premature fetuses. Although these hormones are less sensitive to external stimuli than norepinephrine during fetal age, it was shown that strong external stimuli induce the release of these hormones even in premature fetuses $[19,20]$. The activation of catecholamines and ACTH-cortisol axis during the first few $h$ of EUFI indicates that the fetus experienced enormous environmental changes due to the catheter insertion and connection to extracorporeal circulation.

Changes in plasma concentrations of BUN and CRE were not simple. Both increases and decreas-

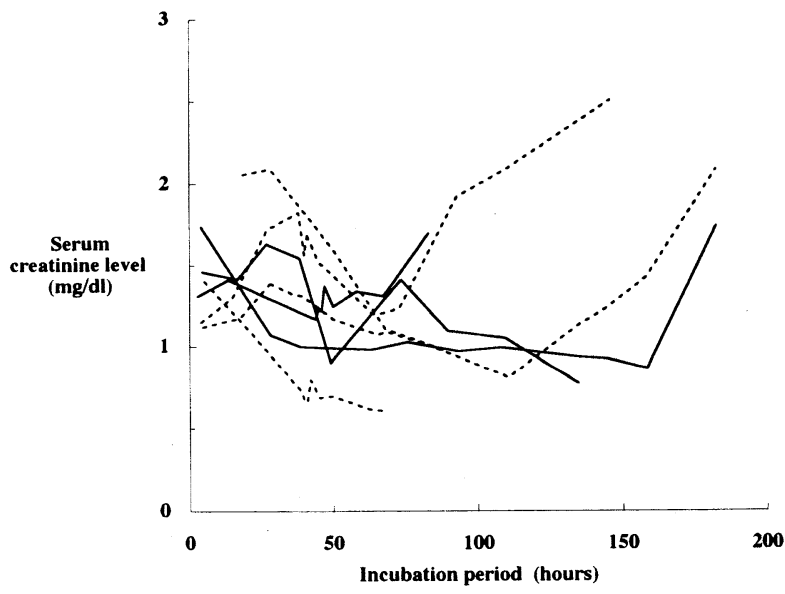

Fig. 7. Serum creatinine concentration of goat fetuses during long-term extrauterine incubation experiment. 
es were observed during the first $40 \mathrm{~h}$ of incubation. This result indicates that fetal renal conditions right after the start of EUFI are not constant. Circulatory disturbances that the fetuses experienced during catheter insertion might result in renal dysfunction. During the initial 20-24 h of EUFI, fetal circulatory conditions were unstable which might cause the early elevation of BUN and CRE. Because renal function in the premature goat fetuses is limited because of their immaturity, slight disturbances in their kidneys could cause impairment of the water balance during EUFI, especially when supportive measures like hemodialysis or hemofiltration were not applied. Therefore we suspected that the renal dysfunction is one of the causal factors of water retention during EUFI. If circulatory disturbances during the initial period of EUFI are the cause of renal dysfunction, the impaired function will possibly recover after long-term stable incubation. However, this remains to be proven because we could maintain stable conditions for only a few days. The elevation of BUN and CRE after $60 \mathrm{~h}$ of incubation was probably related to the circulatory insufficiency that resulted in fetal death.

In this study, we obatained additional information on the responses of premature goat fetuses during EUFI experiments. The pattern of activation of stress reactive hormones indicated that external stimuli during the mid-period of EUFI were not extreme. Impairment of renal function may be associated with the deterioration and the deaths of the fetuses.

\section{Acknowledgment}

The authors thank Mr. Katsuyuki Kuwana, Senko Medical Instrument Manufacturing Co., Ltd., Tokyo, Japan, who gave us great support in establishing and maintaining the extrauterine fetal incubation system. We also thank the Ministry of Education, Science, and Culture of Japan for supporting this investigation with a grant-in-aid for scientific research.

\section{References}

1. Kuwabara $\mathrm{Y}$, Okai T, Imanishi $\mathrm{Y}$, Muronosono $\mathrm{E}$ Kozuma S, Takeda S, Baba K, Mizuno M (1987) Development of extrauterine fetal incubation system using extracorporeal membrane oxygenator. Artificial Organs 11: 224-227.

2. Kuwabara Y, Okai T, Kozuma S, Unno N, Akiba K, Shinozuka N, Maeda T, Mizuno M (1989) Artificial placenta: Long-term extrauterine incubation of isolated goat fetuses. Artificial Organs 13: 527-531.

3. Unno N, Kuwabara Y, Shinozuka N, Akiba K, Okai T, Kozuma S, Mizuno M (1990) Development of artificial placenta: Oxygen metabolism of isolated goat fetuses with arterio-venous extracorporeal membrane oxygenation. Fetal Diagn Ther 5: 189195.

4. Unno N, Kuwabara Y, Shinozuka N, Akiba K, Okai T, Kozuma S, Mizuno M(1992) Development of an artificial placenta: Optimal extracorporeal blood flow in goat fetuses during extrauterine incubation with umbilical arterio-venous extracorporeal membrane oxygenation. Artificial Organs Today 2: 197-204.

5. Nohta H, Mitsui A, Ohkura Y (1984) Spectrofluorimetric determination of catecholamines with 1,2-diphenyl-ethylene-diamine. Anal Chem Acta 165: 171-176.
6. Ito A, Ohbayashi $\mathrm{M}$, Takeda $\mathrm{H}$, Iimuro $\mathrm{F}$, Yonezawa N, Okada M, Ohno H, Iguchi K, Mochizuki T, and Yanaihara N (1989) A sensitive immunoradiometric assay for human adreno-corticotropic hormone. Biomedical Res 10: 491-497.

7. Gilbert RD (1980) Control of fetal cardiac output during changes in blood volume. Am J Physiol 238: H80-H86.

8. Itskovitz J, LaGamma EF, Rudolph AM (1987) Effects of cord compression on fetal blood flow distribution and $\mathrm{O}_{2}$ delivery. Am J Physiol 252: H100-H109.

9. Itskovitz J, LaGamma EF, Rudolph AM (1983) The effect of reducing umbilical blood flow on fetal oxygenation. Am J Obstet Gynecol 145: 813-818.

10. Edelstone DI, Peticca BB, Goldblum LJ (1985) Effects of maternal oxygen administration on fetal oxygenation during reduction in umbilical blood flow in fetal lamb. Am J Obstet Gynecol 152: 351358.

11. Lewis AB, Evans WN, Sischo W (1982) Plasma catecholamine responses to hypoxemia in fetal lambs. Biol Neonate 41: 115-122.

12. Gunn TR, Johnston BM, Iwamoto HS, Fraser M, Nicholls MG, Gluckman PD (1985) Haemodynamic and catecholamine responses to hypothermia in the 
fetal sheep in utero. J Dev Physiol 7: 241-249.

13. Widmark C, Hokegard K-H, Lagercrantz $\mathrm{H}$, Lilja $\mathrm{H}$, Rosen KG (1989) Electrocardiographic waveform changes and catecholamine responses during hypoxia in the immature and mature fetal lamb. Am J Obstet Gynecol 160: 1245-1250.

14. Challis JRG, Richardson BS, Rurak D, Wlodek ME, Patrick JE (1986) Plasma adrenocorticotropic hormone and cortisol and adrenal blood flow during sustained hypoxemia in fetal sheep. Am J Obstet Gynecol 155: 1332-1336.

15. Rose JC, Meis PJ, Morris M (1981) Ontogeny of endocrine (ACTH, vasopressin, cortisol) responses to hypotension in lamb fetuses. Am J Physiol 204: E656-E661.

16. Akagi K, Berdusco ET, Challis JRG (1990) Cortisol inhibits ACTH but not the AVP response to hypoxaemia in fetal lambs at days 123-128 of gestation. J Dev Physiol 14: 319-324.

17. Rose JC, MacDonald AA, Heymann MA.(1978) Developmental aspects of the pituitary-adrenal responses to hemorrhagic stress in lamb fetuses in utero. J Clin Invest 61: 424-432.

18. Jones CT, Boddy K, Robinson JS, Radcliffe JG (1977) Developmental changes in the response of the adrenal glands of fetal sheep to endogenous adrenocorticotrophin, as indicated by hormone response to hypoxaemia. J Endocrinol 72: 279-292.

19. Iwamoto HS, Kaufman T, Keil LC, Rudolph AM (1989) Responses to acute hypoxemia in fetal sheep at 0.6-0.7 gestation. Am J Physiol 256: H613-H620.

20. Hargrave BY, Rose JC (1985) By 94 days of gestation plasma cortisol increases block ACTH response to hypotension in lamb fetuses. Am J Physiol 249: E350-E354. 